\title{
A dupla face de Jano: magistrados, famílias de elite e mediação no extremo sul do Brasil entre 1808 e $1831^{1}$
}

The two faces of Janus: Magistrates, elite families and mediation in south Brazil between 1808 and 1831

Adriano Comissoli ${ }^{2}$

adrianocomissoli@hotmail.com

Resumo. O fenômeno de brokerage implica a mediação entre um espaço social de alcance limitado e outro de maior amplitude. Aplicamos tal leitura à conexão do Rio Grande de São Pedro com a Corte do Rio de Janeiro. Demonstramos como a tessitura de laços familiares entre magistrados nomeados pelo poder central e famílias de elite localmente enraizadas cria uma ponte que integra ambos os espaços oferecendo-lhes um sentido de unidade. Da parte dos magistrados esta união com a elite local permitiu a ascensão aos cargos políticos de tipo representativo surgidos após a emancipação política do Brasil frente a Portugal. Da parte dos estancieiros-militares componentes da elite abriu-se a possibilidade de expressão política de acordo com um novo linguajar que se disseminava rapidamente nos agitados anos de 1820 e 1830. Embora voltado ao Rio Grande de São Pedro, o estudo demonstra a viabilidade da aplicação do fenômeno a outras províncias do Império brasileiro.

Palavras-chave: bacharel, elite, magistrado, mediação.

Abstract. Brokerage is a social phenomenon which implies mediation between societies of different amplitudes. Our study applies such concept to understand connection between the province Rio Grande São Pedro and the Portuguese royal court in the city of Rio de Janeiro. We intend to demonstrate how family bounds between magistrates of Justice nominated by the central power and local elite families creates a link that creates unity between both spaces. To magistrates the union allowed the ascension in the political positions created after the independence of Brazil. To the elite families was given the possibility to express their political interests regarding the new vocabulary that emerged in the 1820's and 1830's. Although we are analyzing the province of Rio Grande de São Pedro we try to demonstrate the viability of the phenomenon to other provinces of the Brazilian Empire.

Key words: bachelor of laws, elite, magistrate, mediation. 
Neste artigo, trato do enraizamento de magistrados de Justiça no Rio Grande de São Pedro do século XIX. A ideia é acompanhar trajetórias procurando perceber o desenvolvimento de relações pessoais que possam ser entendidas como alianças entre os agentes da Coroa portuguesa e famílias de elite da região, tal como demonstra Schwartz (1979) para o Tribunal da Relação da Bahia. O fenômeno adquire relevância na medida em que estes magistrados despontam nos cargos políticos surgidos com a emancipação política do Brasil. Procuro aproximar minhas considerações da ideia de mediação (brokerage) segundo a proposta de Jeremy Boissevain (1974) e de Edoardo Grendi (1978).

Durante o século XVIII, o Rio Grande de São Pedro não contou com um aparelho de Justiça profissional. Nesse período. dispunha somente dos juízes ordinários de sua única Câmara. Sendo apenas dois e não contando com formação em Direito, a apuração de crimes e a administração da Justiça se tornavam bastante limitadas. Nas palavras dos vereadores de Porto Alegre, em 1802, era "impossível, que dois Juízes Ordinários, e esta Câmara possam administrar a tão grandes longetudes [sic]; e por esta causa ficam impunidos [sic] os Crimes dos malfeitores" (AHURS, cx. 6, doc. 428). No ano seguinte o governador Paulo José da Silva Gama fez coro aos camaristas defendendo a criação de novas vilas e o envio de juízes de fora para melhor aplicação da Justiça do rei (Miranda e Martins, 2008,p. 50-51). A solicitação foi endossada pelo Conselho Ultramarino, pois "não só no Rio Grande de São Pedro, senão em todos os lugares dos Domínios Ultramarinos, era muito necessária a Providência que pedia"(AHU-RS, cx. 6, doc. 428). E assim, em 1809, decidiu-se pela divisão do território em quatro vilas e pela nomeação de um juiz de fora para a de Porto Alegre.

Que diferença havia entre um juiz ordinário e um juiz de fora? O primeiro era um morador da comunidade escolhido entre os vereadores, o segundo era um agente designado pela Coroa, por meio do Desembargo do Paço, o qual cursara a Faculdade de Direito. Portanto, temos duas diferenças marcantes: o domínio da cultura jurídica letrada e o alinhamento em relação ao poder central da monarquia portuguesa. Em 1810, tomava posse o primeiro juiz de fora em Porto Alegre, e em 1812 a vila passava a sede da comarca da Ilha de Santa Catarina e Rio Grande de São Pedro, abrigando a residência do ouvidor. Portanto, foi somente no início do século XIX que a Justiça profissional se instalou na capitania.

O juiz de fora operava na primeira instância da Justiça, tendo o ouvidor por superior imediato. No Rio Grande de São Pedro, subordinavam-se ao Tribunal da Relação do Rio de Janeiro, que por sua vez respondia à Mesa do Desembargo do Paço e à Casa de Suplicação em Lisboa. A transferência da família real replicou as duas últimas instituições no Brasil em 1808, e a emancipação em 1822 implicou sua subsequente substituição pelo Supremo Tribunal de Justiça. O juiz de fora atuava simultaneamente como administrador e como ministro de Justiça, presidia a Câmara da vila onde era provido e cuidava dos assuntos municipais junto com os vereadores. No ramo judiciário, tinha alçada nos bens de raiz de até 12 mil réis, nos móveis até 16 mil e nas penas pecuniárias até 4. Efetuava devassas para apurar crimes e operava como fiscal do rei no plano mais imediato da sociedade (Salgado, 1986). A formação profissional do ouvidor não diferia da do juiz de fora, mas em termos jurisdicionais era-lhe superior. Arbitrava questões de até 100 mil réis, além dos crimes ocorridos na comarca. Sua posição garantia amplos poderes sobre outros funcionários, pois ele aprovava as eleições das Câmaras e concedia cartas de confirmação ou de dispensa aos oficiais desta instituição. Acumulava o cargo de corregedor, fiscalizando governadores, presidentes de Província e Conselhos (Salgado, 1986).

Desde 1749 o Rio Grande de São Pedro respondia à comarca da ilha de Santa Catarina. Até 1812, quando a sede da ouvidoria passou para Porto Alegre, o ouvidor realizava apenas visitas ocasionais. Idealmente deveria realizar uma correição a cada ano, mas houve intervalos em que se passaram vários anos sem a mesma ocorrer. Por vezes, algum evento extraordinário exigia a presença do ouvidor na capitania meridional. Quando da criação da Junta da Fazenda Real do Rio Grande de São Pedro, em 1802, o ouvidor passou a exercer também o ofício de juiz executor, embora seguisse morando na vila de Desterro, Ilha de Santa Catarina. Em 1816, criou-se a Junta da Justiça Criminal, tendo no cargo de juiz relator o mesmo ouvidor, além de contar com o governador, juiz de fora de Porto Alegre, juiz da Alfândega, dois vereadores ou dois advogados e um membro nomeado. Mais tarde, quando da criação das varas de juiz de fora para as vilas de Rio Grande e Rio Pardo, estes viriam a compor esta Junta (Miranda, 2000).

Os juízes de fora e ouvidores eram especialistas no Direito, dominando os códigos do sistema normativo da Coroa portuguesa. Entretanto, por operarem em contato direto com as populações locais das diferentes partes do complexo monárquico, eles tinham de relacionar o texto da lei com as realidades específicas. Respeitar as determinações da Coroa era o grande compromisso destes especialistas em leis, mas adequar-se às diferentes condições era seu maior desafio.

Schwartz (1979) dedicou-se a compreender o funcionamento da Justiça portuguesa em terras americanas, percebendo a capacidade de adaptação tanto de magistrados quanto da população frente às normas escritas. A possibi- 
lidade de troca de poder, prestígio e riqueza por parte dos desembargadores da Relação da Bahia com a elite baiana era atrativo suficiente para que a aplicação das leis fosse subordinada aos interesses particulares. A adaptabilidade da magistratura foi percebida no próprio Portugal continental, o que implica afirmar que estes, que deveriam ser agentes do poder monárquico, muitas vezes não atuaram consoante as diretrizes da Coroa (Hespanha, 1984). A figura do juiz de fora é particularmente interessante de ser analisada deste ponto de vista, pois o mesmo atuava em duas instâncias de legitimidades diferentes. Ele era um magistrado de sua majestade o rei de Portugal, mas era responsável também por presidir a Câmara da vila para a qual fosse destacado, o que significa que tinha de lidar diretamente com a manifestação de demandas da elite local. Vejamos um pouco mais do relacionamento entre estes juízes e as famílias mais abastadas da capitania de São Pedro.

Entre 1809 e 1831, foram dez os ministros de Justiça atuantes em Porto Alegre. ${ }^{3}$ Destes, cinco foram juízes de fora, quatro foram ouvidores e um ocupou ambos os cargos. Os juízes se ativeram aos três anos estipulados em suas provisões - entendendo-se que a diferença entre a nomeação de um substituto e sua posse ampliava os intervalos - enquanto os ouvidores, por questões conjunturais, oscilaram algo mais. José Antônio de Miranda teve um mandato particularmente curto, ao deixar o cargo por estar em desacordo com a emancipação brasileira em 1822. Uma ordem expressa do príncipe regente Dom Pedro determinava que pedissem demissão todos os agentes da Coroa que rejeitassem o "sistema brasileiro", ao que o ministro atendeu prontamente. Acreditava que a ruptura entre Portugal e o Brasil era um erro que incidiria na guerra civil (AHU-RS, cx. 13, doc. 819).

Todos os dez magistrados estudaram na Universidade de Coimbra, aprendendo leis e processos e recebendo formação ideológica de tendência uniformizadora. A vida universitária não somente preparava os estudantes enquanto profissionais das leis, mas os dotava de um conjunto de experiências comuns que simultaneamente os diferenciava do restante da sociedade, conferia-lhes sentido de corpo e os alinhava ao serviço régio (Schwartz, 1979; Almeida, 2004). Para José Subtil, essa formação contribuía para a definição do campo de poder dos magistrados, pois ocorria a identificação dos mesmos enquanto grupo distinto dos demais corpos da sociedade do Antigo Regime português (Subtil, 1996).

A obtenção do diploma configurava uma forma de qualificação social dessa mesma sociedade, pois os ba- charéis era considerados integrantes da chamada nobreza civil. Esta era uma camada distinta da nobreza de sangue, mas igualmente dos grupos populares, pois encontrava-se livre da mácula do trabalho manual, situando-se às bordas da aristocracia. Este prestígio e esta diferenciação social aumentavam com o ingresso nos "lugares de Letras", ou seja, para o serviço da Justiça régia, pois os exames de leitura de bacharéis realizavam investigações genealógicas que eliminavam os dotados de defeito mecânico ou hereges religiosos (Subtil, 1996). ${ }^{4}$ Não se permitiam aos descendentes de cristãos-novos ou de trabalhadores manuais o acesso à magistratura, embora pudessem ser conferidas dispensas destes impedimentos. Controlado pelo Desembargo do Paço, o exame de leitura de bacharéis "constituiu um instrumento de controlo e disciplina da magistratura territorial" (Subtil, 1996, p. 298). O resultado em termos sociais era que os ministros da Lei não apenas contavam com formação intelectual superior à maioria, mas igualmente com um atestado de qualidade social privilegiada.

Há mais um elemento a considerar sobre a formação acadêmica dos juízes. Dado o intervalo de tempo abordado, podemos supor que, ao tempo de estudantes, os ministros que posteriormente foram designados para o Rio Grande de São Pedro foram contemporâneos ou entraram em contato direto com o grupo que Kenneth Maxwell (1999) batizou de "geração de 1790". Tratava-se este de estudantes protegidos por Dom Rodrigo de Souza Coutinho, secretário de Estado da Marinha e do Ultramar, que deveriam preparar-se para administrar a monarquia de forma racional, promovendo reformas que apostavam na maior articulação entre suas diversas partes. Para tanto, Dom Rodrigo patrocinava estudos e viagens de estudantes brasileiros visando criar administradores não só mais preparados, como atentos a evitar soluções paliativas e localistas para as vulnerabilidades do sistema político português. Dentre eles podemos citar José Bonifácio de Andrada e Silva, Antônio Pires da Silva Ponte e Manuel Ferreira da Câmara, nomeados, respectivamente, intendente das Minas e Metais, governador da capitania do Espírito Santo e intendente geral das Minas e do Serro Frio.

Se "em 1785, José Bonifácio de Andrada e Silva, um paulista que se matriculara em Coimbra [...] estava escrevendo poemas carregados de uma estonteante profusão de heróis, que incluía Rousseau, Locke, Voltaire, Pope, Virgílio e Camões" (Maxwell, 1999, p. 159), cinco anos depois o bacharel Luís Correia Teixeira de Bragança, futuro juiz de fora de Porto Alegre, realizava seu exame para ingresso na magistratura régia. A proximidade

${ }^{3}$ Contabilizei os juízes de fora a partir de 1809 , ano da posse do primeiro oficial em Porto Alegre, enquanto os ouvidores foram considerados a partir de 1812 , quando passaram a residir na mesma vila.

${ }^{4}$ A expressão defeito mecânico se refere aos homens que executavam ofícios manuais e, portanto, viviam do próprio trabalho, em oposição ao ideal aristocrático de viver do trabalho alheio. 
temporal permite pensar em um ambiente intelectual comum, no qual certas ideias eram compartilhadas, entre elas a do império luso-brasileiro.

Outros de nossos investigados também vivenciaram experiências não acadêmicas diretamente relacionadas às agitações políticas do início do século XIX. Muito antes de se deslocar para o Rio Grande de São Pedro,José Maria de Sales Gameiro Mendonça Peçanha conheceu o futuro "patriarca da independência”. Em 1810, Peçanha integrou o Corpo Acadêmico de voluntários para combater os invasores franceses, do qual José Bonifácio era comandante. Foi este último que atestou os serviços de Peçanha, que "veio imediatamente alistar-se e partiu com ele para se opor ao inimigo" (BNRJ, Documentos biográficos, C 667,7). Outro que se tornaria juiz em Porto Alegre foi Cândido Ladislau Japi-Assú, que ao tempo da independência estudava na universidade e defendeu a legitimidade da causa brasileiro através de um periódico chamado " $\mathrm{O}$ Brasileiro em Coimbra”, o que lhe custou degredo para a Serra da Estrela (BNRJ, Documentos biográficos, C 252, 13). Portanto, os estudantes não apenas se preparavam para a carreira de magistrados, mas igualmente vivenciavam as transformações políticas do período.

Nenhum dos dez juízes era natural do Rio Grande de São Pedro, mas os nascidos na América formavam maioria. Eram três naturais do Reino, três da Bahia, dois do Rio de Janeiro, um de Pernambuco e um de Minas Gerais. Estas capitanias eram justamente as quatro que mais enviaram estudantes para Coimbra (Carvalho, 2003, p.73). Portanto, embora modestos, os números refletem a tendência geral do recrutamento da magistratura do início do oitocentos. Nesse período, os sul-rio-grandenses não enviavam filhos para Coimbra, seja por falta de condições, seja por optarem por outros nichos de poder.

A vila de Porto Alegre, por sua vez, não aparentava ser um local de destaque na carreira jurídica. De modo geral, os magistrados eram nomeados inicialmente para varas pouco importantes, sendo progressivamente remanejados para outras mais relevantes conforme progrediam na carreira. Até onde pude apurar, Porto Alegre foi a primeira nomeação de seis dos ministros que estudei, o que sugere que a vila estava na base de suas carreiras, talvez por sua pouca importância. Entretanto, ao menos um dos juízes discordou dessa avaliação. O citado José Maria Mendonça Peçanha foi nomeado procurador da Coroa no Rio Grande de São Pedro em 1815 com o "módico ordenado" de 100 mil réis por ano. Requerendo o valor de 350 mil, afirmava que nas capitanias de Pernambuco, Ceará, São Paulo, Minas Gerais e Goiás pagava-se entre 250 e 400 mil réis anuais, "quando é certo que algumas destas nem são tão opulentas nem tão trabalhosas como a do Rio Grande" (BNRJ, Documentos biográficos, C 667, 7).
No plano profissional, os dez magistrados se saíram acima da média, visto que mais da metade dos ministros territoriais nomeados entre 1772 e 1826 pelo Desembargo do Paço abandonavam a carreira após a primeira comissão (Subtil, 2002, p. 42). Os que vieram para o extremo sul da América foram mais persistentes. Meus dados apontam que apenas dois desistiram da magistratura após a primeira colocação e que seis desempenharam mais de três comissões. Cinco dos dez chegaram a desembargador em tribunais da Relação. Dois destes, contudo, foram promovidos somente após a independência do Brasil, o que significa que supriam as necessidades da nação emergente, não mais da monarquia portuguesa. De toda forma são carreiras expressivas, pois de 5.249 candidatos às leituras de bacharéis entre 1750 e 1833 somente 2.909 foram aprovados e apenas 1.365 providos (Subtil, 1996, p. 280).

O magistrado sobre o qual mais disponho de informações foi o primeiro juiz de fora de Porto Alegre e, portanto, o primeiro oficial da Justiça profissional a residir na vila, o doutor Luís Correia Teixeira de Bragança. Sua trajetória demonstra, simultaneamente, elementos da relação entre os juízes e as famílias de elite e as opções existentes de mobilidade social na monarquia portuguesa. Nasceu na Vila Real, norte de Portugal, a mesma da qual eram naturais seus pais e avós, "os quais todos nunca tiveram ou exercitaram ofício plebeu, mas antes sempre se trataram com muita decência" (ANTT, letra L, maço 16, doc. 7). O pai foi identificado como bacharel, e os avós "sempre estiveram servindo os empregos honoríficos da República e por isso sempre foram tidos e respeitados por pessoas nobres nesta vila" (ANTT, letra L, maço 16, doc. 7). A família se relacionava com figuras de boa qualidade social, pessoas "de conhecida nobreza", cavaleiros da Ordem de Cristo e fidalgos da Casa de Sua Majestade. Representavam, portanto, a melhor tradição da nobreza política portuguesa (Monteiro, 2003).

Em 1790, dotado desse cabedal simbólico e após formar-se em Direito por Coimbra, Bragança foi aceito nos lugares de Letras. Sua primeira colocação foi a de juiz de fora na Ilha do Pico, arquipélago dos Açores, em 1795, a qual exerceu por cerca de seis anos (BNRJ, Documentos biográficos, C 116, 19). A designação seguinte foi a de ouvidor na comarca da Ilha de Santa Catarina e Rio Grande de São Pedro (1802), na qual colecionou elogios de três governadores e do vice-rei do Brasil, mas também demonstrou voraz apetite por cargos e ordenados. Requereu aumentos e a nomeação para outros ofícios, como o de auditor do regimento da ilha. Outro de seus pedidos dizia respeito à recém criada Junta da Fazenda do Rio Grande de São Pedro, pois o ouvidor da comarca devia atuar como juiz executor na mesma. A Coroa ordenou que Bragança fosse residir em Porto Alegre, e ele requisitou ajuda de 
custo para sua residência e o acréscimo de 400 mil réis pelas atividades na Junta. $\mathrm{O}$ pedido não foi atendido, e o Conselho Ultramarino determinou que o ouvidor fosse substituído por um juiz de fora, tendo Bragança de viver na Ilha de Santa Catarina (AHU-SC, Consulta do Conselho Ultramarino, cx. 9, doc. 444).

Foi durante a ocupação da ouvidoria de Santa Catarina que Bragança foi graduado desembargador da Relação do Rio de Janeiro, mas, não satisfeito, procurou corrigir o repasse das propinas das Câmaras de Porto Alegre, Desterro e Laguna ao secretário da ouvidoria. Em 1805, dado que o juiz de fora nomeado não se dirigia a Porto Alegre e o posto de juiz executor da Junta da Fazenda permanecia vago, requereu sua mudança para a vila a fim de tomar posse do ofício. Lamentava a Dom João ter feito "importantes despesas na inteligência de ir para Porto Alegre, aonde se achava já o seu fato e toda a sua mobília", visando ao cumprimento das ordens que recebera em 1802 (AHU-RS, cx. 9, doc. 566). Informava finalmente que, instado pelo governador a ocupar seu posto na Junta da Fazenda, se dirigira a Porto Alegre disposto a permanecer residindo na vila até que chegasse o juiz de fora nomeado para a mesma.

Muito provavelmente foi durante sua estadia em Porto Alegre que o desembargador Bragança conheceu Josefa Eulália de Azevedo, viúva do brigadeiro Rafael Pinto Bandeira. Em 1807, deram abertura a seu processo de justificação matrimonial, para o que o desembargador e cavaleiro da Ordem de Cristo solicitou e obteve licença de Dom João (AHU-RS, cx. 11, doc. 660). Celebrado o matrimônio, Bragança foi nomeado juiz de fora na vila de Angra dos Reis, na capitania do Rio de Janeiro, por decreto de 29 de maio de 1808 . O magistrado recusou a oferta, pedindo a vara de Porto Alegre, onde vivia sua esposa e podia assumir o posto de juiz executor da Junta da Fazenda. A investigação não encontrou novas nomeações dentro da magistratura para Luís Correia, mas ele ocupou outros postos na administração. Em 1816, tomou posse como deputado na Junta da Justiça e, um ano depois, retornou à Junta da Fazenda, desta vez no cargo de tesoureiro geral. Responsável por tantas tarefas, queixou-se de receber somente 600 mil réis, quando, como desembargador que era, deveria receber ao menos 900. Por fim, solicitou despacho para ingressar na Casa de Suplicação assim que possível (BNRJ, Documentos biográficos, C 116, 19).

O casamento de Bragança não aparenta ser algo fortuito. Sua esposa era viúva do brigadeiro Rafael Pinto Bandeira, herói de guerra frente aos espanhóis, rico estancieiro e praticante de contrabando de gado. Rafael, contando com apoio de irmãos, primos e cunhados, foi uma importante liderança local da capitania na segunda metade do século XVIII. Sua perícia como comandante militar e sua capacidade de arregimentar homens eram tamanhas e tão importantes na manutenção da fronteira lusitana no extremo sul da América que a Coroa o recompensou com o hábito da Ordem de Cristo e com vistas grossas às suas atividades de contrabandista (Hameister e Gil, 2007). Josefa Eulália de Azevedo fora sua terceira esposa, sucedendo uniões que o ligaram a índias minuano e guarani na busca por aliados. A família de Josefa provinha da Colônia do Sacramento e tinha indícios de distinção: um de seus tios era familiar do Santo Ofício, e dois primos estudaram em Coimbra (Kühn, 2006, p. 210). Os irmãos de Josefa casaram com sobrinhas de Rafael (filhas de sua irmã Desidéria), o que implica o estreitamento de laços parentais entre as duas famílias.

Tudo indica que Josefa Eulália sabia atrair bons partidos. Rafael, o primeiro marido, era representante de antiga e poderosa família sul-rio-grandense, herói de guerra e comandante de homens. O segundo marido, o desembargador Bragança, era magistrado do rei, cavaleiro de Cristo e filho da nobreza da Vila Real, distinções que escapavam aos habitantes do Continente. Após a morte de Rafael, ela se tornou tutora das filhas, administrando praticamente todo o patrimônio deixado pelo rico marido (AHU-RS, cx. 5, doc. 389). Ela parece ter herdado mais do que a fortuna de Rafael, trazendo para si parte do prestígio dele, pois o registro de seu segundo casamento anuncia a união do desembargador Luís Correia Teixeira de Bragança com a brigadeira Josefa Eulália de Azevedo (AHCMPA, 2LMPA, fl. 8). A posição social da viúva era tamanha que ela ostentava um curioso título militar, obviamente informal, mas que expressava sua projeção social, reconhecida pelo pároco responsável por tomar o registro do matrimônio. O caso é mais curioso se consideramos que não existe maneira de medir se o desembargador procurou aproximar-se da viúva de Rafael Pinto Bandeira ou se ela buscou o magistrado. Ainda assim, o enlace matrimonial resultou num bem-sucedido somatório de autoridades e legitimidades distintas.

A união do desembargador com a brigadeira, contudo, alterava a posição do primeiro enquanto magistrado do rei, pois, como indica Manuel Antônio de Magalhães, autor do Almanack da Vila de Porto Alegre, Bragança

cuidou em casar-se e estabelecer na casa mais rica da capitania, e há pouco saiu para essa Corte a pedir o lugar de juiz de fora desta, como uma coisa de bagatela, sendo de maior importância, e mais rendoso de toda a América, [...], sendo muito provável que alcance com aquelas vantagens que tem o lugar de criação, enganando S.A.R. e seus ministros (Magalhães, 1867, p. 62). 
Magalhães queixava-se de que, no cargo de ouvidor, Bragança recebera "perto de duzentos autos para despachar, e apenas despachou onze ou doze em todo o tempo que serviu" (Magalhães, 1867, p. 62). Considerava impossível ao ministro realizar com boa conduta as suas obrigações, visto se estabelecer em "uma terra onde sua mulher se vê rodeada de imensos parentes pobres, e na sua casa mil dependências que arrumar, e tratando destas e dos seus particulares interesses, pisam-se as leis, vexam-se os povos e tudo se põe em desordem" (Magalhães, 1867, p. 62). Contudo, parece mais interessante pensarmos de modo inverso, ou seja, que Bragança justamente se casara com Josefa Eulália tendo em vista sua ampla parentela, o que the permitiria perseguir os seus interesses particulares.

A brigadeira Josefa Eulália adicionava às suas relações um elemento até aquele momento indisponível às famílias de elite sulistas, a aliança com magistrados. Ao casar-se com a viúva do brigadeiro, o desembargador Bragança somava aos seus predicados a fortuna herdada por sua esposa e a pertença a uma das redes de poder mais antigas e bem articuladas da região, visto remontar aos avós de Rafael. Não obstante a importância de seus cargos, o matrimônio de Luís Correia colocou-o em posição de negociar apoios e alianças em seu benefício, fosse pela riqueza herdada por sua esposa, fosse pela pertença da mesma à rede dos Pinto Bandeira. Junto com sua atuação administrativa e política, ele construía uma invejável projeção local. De fato, em 1825 ele foi escolhido o primeiro senador do Rio Grande de São Pedro e nomeado desembargador dos Agravos da Casa de Suplicação. Infelizmente, seu falecimento no ano seguinte o impediu de assumir os importantes postos e coroar sua trajetória administrativa e política.

O caso do desembargador e da brigadeira é bastante curioso, mas não passaria de tanto se não fosse apenas o primeiro a ocorrer no Rio Grande de São Pedro. Outros magistrados agiram de forma semelhante. Antes de expor esses outros casos, gostaria de abrir um parêntese para tratar de esclarecimentos teóricos sobre o que estou procurando demonstrar.

Stuart Schwartz já destacara a ocorrência de casamentos entre magistrados e mulheres de famílias da elite onde atuavam, no caso de seu estudo, o Recôncavo baiano. Para ele, havia motivos bastante claros para os matrimônios, que eram "o método mais eficiente de incorporar magistrados na sociedade local de forma permanente" (Schwartz, 1979, p. 271). Nessa fusão entre burocracia e famílias aristocráticas, "os juízes pareciam oferecer poder e prestígio que beneficiariam diretamente a família”, enquanto que para os desembargadores interessavam a riqueza e as propriedades de que dispunham seus novos parentes (Schwartz, 1979, p. 271). O historiador chamou esse fenômeno de "abrasileiramento" da burocracia real lusitana, indicando com isso que o comportamento dos desembargadores da Relação da Bahia passava a ser fortemente orientado por seu pertencimento a essas famílias mais do que por sua obediência às leis escritas de Portugal. Aparentemente uma falha, essa situação ampliava a integração entre o Estado e a sociedade, oferecendo maior coesão à monarquia portuguesa.

A situação não se encerrou com o fim do status colonial. Como defende Elaine Sodré (2009), após a emancipação brasileira observa-se uma linha de continuidade com o período anterior. No caso da Justiça entre 1833 e 1871, a autora explica que se observam duas formas de atuação, sendo a primeira de acordo com os interesses estatais imperiais e a segunda ligada aos interesses locais. Indo além, ela argumenta que a própria consolidação e manutenção do Estado dependia desse entrelaçamento. Constatações como as de Sodré e Schwartz nos conduzem a perceber não somente o quadro sociológico dos ministros, mas interligá-lo com sua atuação concreta e com as relações estabelecidas com os moradores das localidades onde serviam. Desta forma, "diríamos que a acção política dos burocratas é determinada por elementos estruturais, mas sobredeterminada por elementos biográficos e empíricos" (Hespanha, 1984, p. 81). O contraste entre o projeto do centro de poder e a atuação dos juízes termina por expressar a própria tensão entre norma e prática na sociedade.

Uma vez que esses magistrados, tais como o citado Luís Correia Teixeira de Bragança, atuavam na fronteira de interesses, conectando poderes e legitimidades diversas, talvez seja interessante interpretarmos sua atuação sob a forma de mediação (brokerage). Jonas Vargas (2010) utilizou a noção de mediação política com bons resultados para o final do II Reinado brasileiro. É verdade que juízes e magistrados não foram o alvo de sua investigação, mas sim deputados, senadores e ministros. Entretanto, o mecanismo de ligação entre estes e as províncias que representavam me interessa na medida em que demonstra que a política formal passava por ligações pessoais. Através dos casamentos, amizades e compadrios, fortaleciam-se os laços que ligavam a elite provincial e a elite dirigente da Corte.

Do que trata o fenômeno da mediação? Acredito que uma boa forma de explicá-lo é recorrer à metáfora utilizada por Edoardo Grendi (1978) sobre a face de Jano (faccia de Giano). Na mitologia romana, Jano era um deus dotado de duas faces, capaz de olhar para dois lados simultaneamente. Olhar para os dois lados significa ser capaz de conectar duas realidades distintas, uma imediatamente local e outra mais ampla. $\mathrm{O}$ fenômeno de conexão pode ser de natureza cultural, econômica ou política, interligando uma comunidade específica a outra mais ampla (p. ex.: Igreja 
Católica, mercado, Estado). A possibilidade da mediação se afirma na medida em que sujeitos ou grupos ocupam espaços fundamentais na comunicação entre a esfera local e a mais ampla, restringindo ou monopolizando os canais de acesso entre ambas e tornando-se necessários tanto aos habitantes da comunidade quanto aos representantes do construto mais abrangente (Boissevain, 1974). Estes mediadores ou brokers apresentam, portanto, a visão voltada tanto "para dentro" quanto "para fora" da comunidade, exercendo considerável influência na relação entre espaços sociais.

Grendi utilizou a metáfora da face de Jano para explicar a integração de economias aldeãs à economia de mercado. Ao esclarecer suas ideias, valeu-se de um exemplo baseado na mediação política entre o Estado italiano e a máfia siciliana. Dotada do controle da comunicação entre a comunidade local e o mundo externo por meio do monopólio da força, a máfia controla a manifestação de demandas entre as duas esferas, fazendo-se assim indispensável para a articulação da estrutura social. A interpretação deixa de perceber a rede criminosa somente como excrescência ou oposição ao sistema, passando a percebê-la como parte do mesmo, ainda que ilegal. Grendi sugere, portanto, abandonar o simples registro de normas escritas para o entendimento da sociedade, considerando o mesmo em relação às práticas legais e ilegais existentes, pois somente pela síntese destas características é possível conceber um modelo explicativo satisfatório. Foi esta também a postura de Schwartz, de Sodré e de Vargas e é a proposta que procuro aplicar.

Ao estender a noção de mediação aos magistrados no Rio Grande de São Pedro do início do século XIX, procuro explicar sua ascensão aos cargos políticos que surgem após a independência. Se, nas famílias estudadas por Vargas, havia um investimento na educação e na formação intelectual de seus próprios membros, não é isso que ocorria no início do oitocentos. As famílias de elite optaram por atrair para suas redes juízes que eram oriundos de outras regiões, replicando o que ocorria em torno da Relação da Bahia. Estes novos integrantes foram considerados mais aptos para os postos políticos conforme os mesmos surgiam na década de 1820 , preenchendo cargos no Senado e na Câmara de Deputados logo na primeira eleição aos mesmos. Vamos conhecer mais alguns casos para que a história do desembargador Luís Correia não pareça um acontecimento isolado.

Caetano Xavier Pereira de Brito e José Maria de Sales Gameiro Mendonça Peçanha tiveram percursos semelhantes ao do desembargador Bragança. O primeiro era natural do Recife e de uma boa família da cidade. O pai era familiar do Santo Ofício, e tanto Caetano quanto o irmão estudaram em Coimbra, respectivamente Direito e Medicina. O irmão, Francisco, chegou a vereador na cidade natal, além de participar na Revolução de 1817 e na Confederação do Equador em 1824 (Souza, 2007, p. 775-776). Ao seu modo, Caetano viveu agitações políticas também, pois esteve à frente do juízo de fora de Porto Alegre entre 1820 e 1825 , os anos turbulentos do processo emancipatório. Ele foi rendido, junto com outras autoridades da capitania, pelo motim de abril de 1821 e mais tarde, à frente da Câmara, teve de organizar as eleições para a Junta de Governo Provisório, enfrentando a pressão de oficiais civis e militares, de padres e do povo, que exigiam a criação de um "governo representativo"(Comissoli, 2011).Em meio a esses eventos, ele ajustou para casar-se com Francisca, natural de Porto Alegre e filha do coronel Manuel Godinho Leitão de Alboim. O matrimônio, para o qual o juiz solicitou e obteve licença do príncipe regente Dom Pedro, ocorreu no ano de 1822. Do casamento resultaram três filhos, que herdariam os bens de Caetano quando este viesse a falecer em Porto Alegre em torno do ano de 1833, quando seu inventário foi registrado. $\mathrm{O}$ juiz de vara branca foi a Porto Alegre para cumprir três anos, mas acabou por fazer da vila sua moradia definitiva.

Sua atuação em meio aos eventos da independência do Brasil não passou despercebida nem à nova Corte nem aos homens envolvidos na vida política da região. Seus esforços pela causa do Brasil the renderam em 1823 um Hábito de Cristo, e em 1825 foi nomeado Cavaleiro da Ordem do Cruzeiro. Em 1824, elegiam-no para o Conselho Geral da Província como $13^{\circ}$ mais votado de um total de 21 indicados. O Conselho, apesar de criado, não chegou a operar, já que suas atividades dependiam de legislação reguladora, só criada em 1828. Tanto melhor para Caetano, pois em 1826, após deixar o cargo de juiz de fora, ele foi escolhido deputado para a Câmara Geral no Rio de Janeiro. A experiência no delicado momento de desligamento de Portugal o projetou, beneficiando-o no primeiro momento de manifestação da política do novo regime e colocando-o como representante da Província diretamente na Corte brasileira, ainda que não fosse natural da mesma. Da parte dos habitantes do Rio Grande de São Pedro, a escolha se justificava pelo conjunto de qualidades pessoais e sociais do deputado. Formado em Direito, ele dispunha de educação invulgar, que se somava à recente experiência política, à ligação com uma família da terra e à ostentação de signos distintivos das Ordens Honoríficas. A estas características podemos adicionar a vontade de exercer o controle dos pontos de contato entre o sistema local e o imperial.

José Maria de Sales Gameiro Mendonça Peçanha viveu praticamente a mesma situação de seus colegas juízes; o diferencial encontra-se no fato de ter exercido mais cargos que os demais na região. Natural do Rio de Janeiro e filho do desembargador José Feliciano Rocha Gameiro, ele estudava Direito em Coimbra em 1809 e, 
como vimos, se envolveu no combate aos franceses. Em 1816, requisitou ser designado para o lugar de juiz de fora em Porto Alegre ou para o de juiz do crime do bairro de Santa Rita no Rio de Janeiro (BNRJ, Documentos biográficos, C 667, 7). Recebeu o primeiro. Entre 1817 e 1820, viveu na capital rio-grandense e, ao fim do período, foi designado para a vila de Rio Pardo, na mesma capitania, para assumir a recém criada vara de juiz de fora. Em 1823 foi promovido a ouvidor da comarca do Rio Grande de São Pedro, e permaneceu neste cargo até 1828. Foram cerca de dez anos desempenhando sucessivos cargos de Justiça na capitania, o que contribuía para torná-lo uma referência no campo do Direito.

Entre as idas e vindas das vilas de Porto Alegre, Rio Pardo e São João da Cachoeira, Peçanha teve trato com a sociedade local. Dentre as pessoas que conheceu estava a filha de João de Deus Mena Barreto, militar experiente e influente, com quem Peçanha veio a casar-se. Barreto tinha filhos colocados nas tropas, mas, ao casar uma filha com o magistrado, adquiria um aliado capaz de operar em um campo que antes lhe estava fechado, o da Justiça régia. Assim, Barreto assumiu a presidência da Junta de Governo Provisório em 1822, e Mendonça Peçanha passou a ouvidor no ano seguinte, ampliando a influência desta família no aparato oficial em momento de reorganização de legitimidades. Essa concentração de poderes na família Mena Barreto não passou despercebida aos contemporâneos. Um deles, acreditando-se perseguido, denunciou Peçanha como títere do sogro, acobertando a ele e aos cunhados; "um magistrado que assim procede está convencido de ignorante, ou de servil a seu absoluto sogro e seus particulares interesses"(AHRS, 1984, p. 159165). O acusador referia-se ao "ímpio Presidente Barreto e seus nefandos sócios", dentre eles “o injusto Ouvidor”. As acusações e o processo em si aguardam uma investigação mais detalhada, mas indicam a ação conjunta dos Mena Barreto e de Peçanha em perseguir seus inimigos políticos por meio do domínio dos poderes oficiais.

O casamento e a carreira na magistratura ofereceram projeção política a Peçanha, que lhe garantiu a entrada no Conselho Geral da Província em 1828 e 1829 e novamente em 1833, quando foi seu presidente. $\mathrm{Na}$ transformação do Conselho em Assembleia Legislativa Provincial em 1835, o antigo juiz seria escolhido deputado, participando da mesma em 1835 e 1836 e acompanhando os debates que eclodiriam na guerra civil de 1835-1845. É muito provável que viesse a acompanhar a posição legalista dos cunhados e do sogro, que logo deram combate aos insurgentes e procuraram garantir a unidade nacional no extremo sul.

A magistratura enquanto corpo burocrático era uma das mais importantes elites da monarquia portuguesa. Sua formação universitária em Direito delimitava um campo de saber específico e, por meio de uma formação comum, operava a disseminação e aplicação de uma base jurídica homogênea, cuja fonte legitimadora era a Coroa. Os magistrados se encontravam numa zona intermédia da sociedade que compunha a chamada nobreza civil ou política. Mais próximos ao rei do que a maioria dos vassalos e realizando serviços mais relevantes, os magistrados ocupavam uma posição mais central no espectro de valores sociais. Comparada à alta nobreza ou à elite eclesiástica, a magistratura conformava uma elite aberta, por não desenvolver padrões excludentes ao seu exercício. Uma vez que um sujeito ingressava no corpo de ministros, sua progressão na carreira seria capaz de permitir o acesso aos mais altos postos pelo mérito individual e capacidade profissional (Subtil, 1996).

No caso aqui estudado, os ministros do rei aproveitaram suas nomeações para o extremo sul da América portuguesa para construírem uma aliança definitiva com a elite com a qual entraram em contato. Como pontuou Schwartz, os magistrados contavam com um prestígio e uma educação acima da média mesmo se comparada com as famílias de elite, isso porque, como defendeu Subtil, os juízes operavam em um campo de poder específico. Essa diferenciação se potencializava na sociedade sulista, que não contava com magistrados saídos de suas próprias fileiras e dispunha de pouquíssimos sujeitos formados em Direito. Parece ter sido esse diferencial que fez com que a elite sul-rio-grandense escolhesse os antigos juízes como seus representantes políticos, em especial em arenas localizadas no novo centro político, a Corte do Rio de Janeiro.Joaquim Bernardino de Sena Ribeiro da Costa, por exemplo, foi ouvidor em Porto Alegre entre 1814 e 1823. Ao longo deste período, foi mencionado como irmão de mesa da Misericórdia da vila juntamente com os proprietários de terra e os comerciantes locais. Atuando como ministro do rei, mas dividindo sociabilidades com a elite local, ele terminou por ser escolhido como deputado da Assembleia Constituinte em 1823, encarregado de defender os interesses políticos do Rio Grande em momento bastante delicado.

O exemplo de José Teixeira da Matta Bacellar, juiz de fora da vila de Rio Grande entre 1819 e 1822, ajuda-nos a perceber que esta não era uma situação restrita ao sul da América. Ao desembarcar na vila meridional, Bacellar já havia construído uma sólida carreira no nordeste brasileiro. Natural de Coimbra e formado em Direito ele exerceu a advocacia por nove anos na cidade da Bahia. Não satisfeito, dirigiu-se a Lisboa para prestar o exame de leitura de bacharéis e suplicar um emprego ao príncipe Dom João. Alcançou sua pretensão, sendo nomeado provedor dos defuntos e ausentes em Salvador e, logo após, ouvidor da comarca de Sergipe. No ano de 1820, foi provido desembargador da Relação da Bahia. As relações que desenvolveu no nordeste mostraram-se fortes e duradouras, pois, apesar de se dirigir ao Rio Grande de São 
Pedro, onde fora escolhido para a Junta de Governo Provisório em 1822, Bacellar foi eleito senador pela Província de Sergipe em 1825 (BNRJ, Documentos biográficos, C 214, 9). Neste cargo permaneceu até sua morte em 1838 , e, embora os laços desenvolvidos no nordeste tenham prevalecido, sua trajetória demonstra o mesmo tipo de ascensão política identificada para o caso sulista.

Colocados na posição de representantes políticos oficiais da elite sulista, os antigos magistrados faziam o papel de mediadores políticos. Eles já compartilhavam laços, sociabilidades e interesses suficientes para serem identificados como membros daquela sociedade, contudo, sua trajetória de funcionários da Justiça os tornava mais aptos a dialogarem com o centro do poder. Eles dispunham de maior domínio sobre o funcionamento e elaboração das leis e uma formação intelectual mais apurada frente aos grandes proprietários de terra do Rio Grande de São Pedro. Paralelamente, contavam uma legitimidade que passava pelo serviço direto ao monarca e por diversos signos de distinção, como a chamada limpeza de sangue e a inclusão em ordens honoríficas.

Acredito que estes predicados tenham sido particularmente atraentes à sociedade sulista, que acreditou ser o desembargador Bragança e seus pares os homens mais aptos a atender suas demandas frente ao sistema de governo que se estabelecia concomitantemente à emancipação. É fundamental considerar que, nesse momento, um novo vocabulário político se estabelecia, e, dentro deste, a referência ao liberalismo oferecia novas ideias e novos significados. Os magistrados aqui analisados se aproximam não somente da geração de 1790 , mas igualmente do que Neves chamou de elite coimbrã, grupo originário de famílias bem estabelecidas e que não apenas cursou faculdade em Coimbra, como desempenhou papel de relevo no processo emancipatório e dentro do qual podemos incluir "os que adotaram uma postura e práticas políticas a favor do movimento constitucionalista de 1820" (Neves, 2003, p. 87). Os magistrados aqui estudados tiveram contato com os membros dessa elite política e intelectual atuantes na capitania de São Pedro e considerados na análise de Neves: José Antônio de Miranda, Antônio Vieira da Soledade, João de Santa Bárbara e José Feliciano Fernandes Pinheiro (Comissoli, 2011). Como se vê, eles eram não apenas ministros do rei, mas atores políticos e membros de um grupo intelectual bastante restrito.

O panorama descrito e a aliança entre a elite local e os magistrados expressa por meio de casamentos foram fundamentais para a escolha destes antigos juízes para os novos cargos políticos surgidos no I Reinado brasileiro. A noção de broker permite pensar estes agentes como capazes de operar em dois mundos: o das vilas meridionais e o da Corte fluminense. De certa forma, eles pertenciam a ambos, o que os tornava aptos a interligá-los. Podem ser considerados fiéis servidores do monarca tanto quanto representantes da elite local. Não que eles mudassem de lado, mas, antes, inexistiam lados distintos e excludentes. Visto que o Estado necessitava do apoio dos membros da elite local - dada sua capacidade de organizar e mobilizar a população -, a atuação dos mediadores apresentava uma ação pragmática no interesse de alcançar estes líderes locais. O contato entre a sociedade imediata e a comunidade imaginada da nação apresentava vácuos, pontos que não se conectavam com clareza, oferecendo espaço para estes mediadores. Esta dualidade era, em grande medida, garantida por sujeitos ou grupos capazes de estabelecer e manter conexões entre estes universos conflitantes. Estes mediadores conheciam o funcionamento e os valores de ambas as sociedades, estando aptos a "traduzir" suas linguagens e, assim, tornar conexas as aparentes incompatibilidades do sistema social.

A capacidade de mediação, contudo, dependia não somente do controle das normas legais, mas igualmente das relações pessoais que os magistrados possuíam em ambas as esferas. Se, de um lado, os juízes eram enviados pela Coroa como elemento externo à comunidade, é incorreto afirmar que eles estivessem apartados da mesma ou que não dispusessem da habilidade ou do interesse em construir laços com seus habitantes. Portanto, ao ligar-se simultaneamente à comunidade local e ao Estado, os magistrados eram capazes de exercer considerável influência política, pois sua face de Jano lhes permitia olhar tanto "para dentro" da vila quanto "para fora" em direção ao sistema mais amplo (o Império português e, mais tarde, o brasileiro). A cadeia de relações interpessoais, das quais os juízes e os ouvidores eram elo articulador, formava um continuum entre as esferas socioespaciais, gerando coerência e alguma unidade para as partes desconexas do Brasil do início do oitocentos. No caso específico de nosso estudo, a capacidade de mediação dos magistrados se mostrou ativa não somente pelo exercício da Justiça, mas igualmente pelos sólidos laços que construíram com a elite sul-rio-grandense, a ponto de serem escolhidos para representá-la oficialmente nas arenas políticas de alcance nacional do pós-independência.

\section{Conclusão}

A utilização da noção de mediadores ou brokers nos permite uma leitura bastante interessante dos oficiais de Justiça. Aqui a questão se desloca um pouco da oposição entre centralização e autonomia local para a da conexão entre duas esferas de poder diferentes. Com isso é possível compreender a formação de um complexo político amplo, mas igualmente a permanência e o vigor das lideranças 
locais. No momento de transformações do início do século $\mathrm{XIX}$, os magistrados se mostraram capazes tanto de prestar serviço ao poder central quanto de ingressar nas famílias de elite sulistas. Essa habilidade os coroou como primeiros representantes nas novas arenas políticas. Com o tempo,o fenômeno de mediação sofreria transformações e, em vez de se recrutarem juízes oriundos de outras regiões, passouse a enviar os filhos destas famílias de elite para estudar nas universidades. No final do século XVIII e início do XIX, esta possibilidade era bastante limitada. Neste momento, a consolidação do aparelho de Justiça oficial abriu a porta para arrivistas, que, por controlarem um campo de poder específico, foram bem recebidos pelos chefes locais, em particular militares terratenentes. $O$ resultado foi não o antagonismo entre centro e periferia, mas a convivência e mesmo aliança entre representantes das duas esferas, o que garantia a ligação entre a Corte e a fronteira.

\section{Referências}

ALMEIDA,J.E. de. 2004. A forja dos homens: estudos elugares de poder no séc. XVII. Lisboa, Imprensa de Ciências Sociais, 189 p.

BOISSEVAIN, J. 1974. Friends of Friends: Networks, Manipulators and Coalitions. Oxford, Basil Blackwell, 285 p.

CARVALHO, J.M. 2003. A construção da ordem: a elite politica imperial ET Teatro de sombras: a política imperial. Rio de Janeiro, Civilização Brasileira, $459 \mathrm{p}$.

COMISSOLI, A. 2011. A serviço de Sua Majestade: administração, elite e poderes no extremo meridional brasileiro (1808c.-1831c.). Rio de Janeiro, RJ. Tese de Doutorado. PPGHIS-UFRJ, 389 p.

GRENDI, E.1978. Polanyi:Dall'antropologia economica alla microanalise storica. Milano, Etas Libri, 179 p.

HAMEISTER,M.D.; GIL,T.L. 2007. Fazer-se elite no extremo sul do Estado do Brasil: uma obra em três movimentos: Continente do Rio Grande de São Pedro (século XVIII). In:J.L.R. FRAGOSO; C.M.C. de ALMEIDA; A.C.J. de SAMPAIO, Conquistadores e negociantes: histórias de elites no Antigo Regime nos trópicos: América lusa, séculos XVI a XVIII. Rio de Janeiro, Civilização Brasileira, p. 265-310.

HESPANHA, A.M. 1984. Para uma teoria da história institucional do Antigo Regime. In: A.M. HESPANHA, Poder e instituiçôes na Europa do Antigo Regime. Lisboa, Fundação Calouste Gulbenkian, p. 7-89.

KÜHN, F. 2006. Gente da Fronteira: família, sociedade e poder no sul da América Portuguesa - século XVIII. Niterói, RJ.Tese de Doutorado. Universidade Federal Fluminense, 479 p.

MAXWELL, K. 1999. A geração de 1790 e a idéia do império lusobrasileiro. In: K. MAXWELL, Chocolate, piratas e outros malandros: ensaios tropicais. São Paulo, Paz e Terra, p. 157-207.

MIRANDA, M.E. 2000. Continente de São Pedro: a administração pública no periodo colonial. Porto Alegre, Assembléia Legislativa do Estado do Rio Grande do Sul/Ministério Público do Estado do RS/CORAG, 196 p.

MIRANDA, M.E.; MARTINS, L.B. (coords.). 2008. Capitania de São Pedro do Rio Grande: correspondência do Governador Paulo José da Silva Gama 1808. Porto Alegre, CORAG, 208 p.
MONTEIRO, N.G. 2003. Elites e poder: entre o Antigo Regime e o liberalismo. Lisboa, Imprensa de Ciências Sociais, 333 p.

NEVES, L.M.B.P. das. 2003. Corcundas e constitucionais: a cultura politica da independência (1820-1823). Rio de Janeiro, Revan/ FAPERJ, $480 \mathrm{p}$.

SALGADO, G. (coord.). 1986. Fiscais e meirinhos: a administração no Brasil colonial. Rio de Janeiro, Nova Fronteira, 452 p.

SCHWARTZ, S. 1979. Burocracia e sociedade no Brasil colonial. São Paulo, Editora Perspectiva, $354 \mathrm{p}$.

SODRÉ, E.L. de V. 2009. A disputa pelo monopólio de uma força (i) legitima: Estado e Administração Judiciária no Brasil Imperial (Rio Grande do Sul, 1833-1871). Porto Alegre, RS. Tese de Doutorado. PPGH, PUCRS, 415 p.

SOUZA, G.F.C. de. 2007. Elite y ejercicio de poder real en el Brasil colonial: la Cámara Municipal de Recife (1710-1822). Salamanca, Espanha. Tese de Doutorado. Universidad de Salamanca, $937 \mathrm{p}$.

SUBTIL, J. 1996. O desembargo do Paço (1750-1833). Lisboa, EDUAL, $583 \mathrm{p}$.

SUBTIL, J. 2002. Os ministros do rei no poder local, ilhas e ultramar (1772-1826). Penélope, 27:37-58.

VARGAS, J.M. 2010. Entre a paróquia e a corte: os mediadores e as estratégias familiares da elite política do Rio Grande do Sul (1850-1889). Santa Maria, Ed. da UFSM, 294 p.

\section{Fontes primárias}

ARQUIVO HISTÓRICO DA CÚRIA METROPOLITANA DE PORTO ALEGRE (AHCMPA.). 2LMPA. Livro de Registro de Matrimônio da Freguesia de N. Sra. Madre de Deus de Porto Alegre, vol. 2.

ARQUIVO HISTÓRICO ULTRAMARINO - RIO GRANDE DO SUL (AHU-RS). Manuscritos Avulsos da Capitania do Rio Grande do Sul 1732-1825 (CD-ROM do Projeto Resgate Barão do Rio Branco).

ARQUIVO HISTÓRICO ULTRAMARINO - SANTA CATARINA (AHU-SC). Manuscritos Avulsos da Capitania de Santa Catarina 1717-1827 (CD-ROM do Projeto Resgate Barão do Rio Branco).

ARQUIVO HISTÓRICO DO RIO GRANDE DO SUL (AHRS). 1984. Anais do Arquivo Histórico do Rio Grande do Sul. Porto Alegre, AHRS, vol. 8, 473 p.

ARQUIVO NACIONAL DATORRE DOTOMBO (ANTT). Mesa do Desembargo do Paço - Leituras de bacharéis de Luís Correia Teixeira de Bragança, letra L, maço 16, doc. 7.

BIBLIOTECA NACIONAL DO RIO DE JANEIRO (BNRJ). Setor de manuscritos. Documentos biográficos: C 116, 19; C 214, 9; C 252,13; C 667, 7.

MAGALHÃES, M.A. de. 1867. Almanack da Vila de Porto Alegre. Revista do Instituto Histórico e Geográfico Brasileiro, 30:43-74.

Submetido: 01/03/2012 Aceito: 05/06/2012

Adriano Comissoli

Universidade de Passo Fundo

BR 285,s/n, Bairro São José

99052-900, Passo Fundo, RS, Brasil 